\title{
Modeling and Analysis of an LCC HVDC System Using DC Voltage Control to Improve Transient Response and Short-Term Power Transfer Capability
}

\author{
Do-Hoon Kwon, Student Member, IEEE, Young-Jin Kim, Member, IEEE, and Seung-Ill Moon, Senior Member, IEEE
}

\begin{abstract}
A new control method for a line-commutated converter-based (LCC) high-voltage direct-current (HVDC) system is presented and compared to a conventional strategy. In the proposed method, both the DC voltage and current of an LCC HVDC system are regulated to increase the short-term operating margin of DC power transfer and improve transient responses to DC power references. In particular, an increased operating margin of DC power transfer is achieved via the DC voltage regulation method. To verify the effectiveness of the proposed method, a state space model of an LCC HVDC system is developed considering $\mathrm{DC}$ voltage and current references as input variables and analyzed for various values of the DC line inductance and converter controller gains. The state space model can be used for time-efficient analyses of the dynamic characteristics of an LCC HVDC system. Simulation case studies are performed using MATLAB, where the state space model of the Jeju-Haenam HVDC system is implemented as a test case and compared to its comprehensive PSCAD model. The case study results suggest that the proposed method increases the short-term operating margin and speeds up the transient response of the HVDC system. Therefore, it will effectively improve real-time grid frequency regulation.
\end{abstract}

Index Terms-DC power transfer, DC voltage regulation, frequency regulation, LCC HVDC system, operational margin, state space model, transient responses.

\section{INTRODUCTION}

$\mathrm{H}$ IGH-voltage direct-current (HVDC) systems have played an important role in delivering DC power between transmission networks, mainly by exploiting the fast responses of AC/DC power converters to reference signals, e.g., reference DC power [1]. In particular, line-commutated converter-based (LCC) HVDC systems have been used in practice not only for constant DC power delivery between transmission networks but also for grid frequency control, networking with wind farms, and improved grid stability after a severe disturbance [2]-[5]. Among these applications, regulating DC power delivery for frequency control is particularly important for the stable and efficient operation of transmission networks. For example, a 184-kV 150-MW LCC-HVDC system was installed by the Korea Electric Power Corporation (KEPCO) to convey electrical power from the Haenam Substation on the Korean mainland to the Jeju Substation on Jeju Island, via 100-km

Manuscript received July 7, 2017; revised October 22, 2017 and December 21, 2017. This research was supported in part by a National Research Foundation of Korea (NRF) grant funded by the Korea government (MSIP) (NRF-2016R1E1A1A01941191). (corresponding author: Y. Kim).

D. H. Kwon and S. I. Moon are with the School of Electrical Engineering and Computer Science, Seoul National University, Seoul 151-742, Korea.

Y. Kim is with the Department of Electrical Engineering, Pohang University of Science and Technology, Pohang, Gyungbuk 790-784, Korea (e-mail: powersys@postech.ac.kr). undersea cables [6]. It has been recently retrofitted with the additional capability to control DC power for frequency regulation in the Jeju Island network [7].

Various methods for controlling DC power have been developed for LCC HVDC systems in previous studies [8]-[10]. For example, in [8], an LCC HVDC system was studied for controlling active power in an offshore wind farm by regulating the rectifier firing angle or DC-link current. In [9], an additional DC power controller at the inverter side was proposed to suppress the grid frequency variation during the black-start procedure. In [10], a droop controller was implemented in the feedback loop of the rectifier so that the LCC HVDC system cooperated with wind farms for active power control. However, for the HVDC systems discussed so far, only the DC current was controlled for DC power regulation, affecting the DC voltage indirectly and marginally. In fact, a DC-link capacitor can be used as an energy storage device. It absorbs and releases power, respectively, as the voltage is increased and decreased. For example, the inertia emulation strategy was proposed in [11] to control the DC voltage within the range from approximately 0.983 pu to 1.040 pu for a 5\% change in the load demand. Furthermore, it was reported in [12] and [13] that the DC cable insulation was tested with DC voltages 1.45 and 1.85 times higher than the rated voltage, respectively. In addition, the DC voltage applied to the thyristor valves during the 30-minute overvoltage test was 1.3 times higher than the rated voltage [14]. This implies that HVDC systems can operate with overvoltages for short periods of time. Overcurrent is somewhat detrimental to DC lines and converters and hence DC current is normally limited to the rated value. Recently, adjustment of the DC voltage directly has been proposed to regulate the reactive power of the LCC HVDC system in coordination with shunt capacitors [15]; however, that study focused only on reactive power, and additional IGBT-based switches were required to implement the control scheme.

To develop such control methods, the transient responses of LCC HVDC systems have been analyzed, for example, by using the techniques of small signal assessment and transient stability analysis, as well as electromagnetic transient (EMT)type simulators [16]-[20]. In particular, eigenvalue-based small signal assessment techniques provide informative insights into dynamics analysis of complex systems. Using these techniques, state space models of an LCC HVDC system were developed to analyze the interaction between multi-infeed LCC HVDC systems and a wind farm in a weak power network [16], [17]. In [18], a small-signal dynamic model of an LCC HVDC system was developed in a synchronous rotating $d-q$ reference frame by means of the sampled-data modeling approach. In [19], a 
small signal model of an LCC HVDC system was developed in the frequency domain to improve the performance of the DC current controller at the rectifier. In [20], an LCC HVDC system was represented using a linearized state space model. However, the input variables of the small signal models discussed in [16]-[20] included the extinction angle reference, rather than the DC voltage reference. The extinction angle is less intuitive for DC power calculations. Furthermore, only the state space model of the converters was presented; for example, in [20], interactions between the converters connected through the DC line were not considered.

This paper proposes a new control method for an LCC HVDC system by directly adjusting both DC voltage and current, particularly to improve the transient response and short-term operating margin of DC power transfer, which are important in HVDC systems participating in grid frequency regulation under normal $\mathrm{AC}$ grid conditions. A state space model of the LCC HVDC system is developed to verify the effectiveness of the proposed method. Root locus analyses of the state space model are then comprehensively performed to estimate the effects of DC line inductance and converter controller gains on the transient response of the LCC HVDC system. Additionally, simulation case studies are carried out using MATLAB, with the state space model of the Jeju-Haenam HVDC system implemented as a test case and compared to its comprehensive PSCAD model. In the author's previous paper [21], the PSCAD model was developed using real HVDC system parameters and verified through comparison with actual operating data on transient DC voltage and current variations. The main contributions of this paper are summarized below:

- A new control method for an LCC HVDC system is proposed to improve the short-term operating margin of DC power transfer and the transient response by directly regulating both the DC voltage and current. This consequently enables the improvement of real-time grid frequency regulation in power grids, including the HVDC system.

- A state space model of the LCC HVDC system is developed considering both DC voltage and current references as input variables. A new set of differential equations is derived to relate the variations in the actual DC voltage and current with those in the corresponding references.

- Root locus analyses of the state space model are performed for various values of the DC line inductance and converter controller gains, showing their effects on the stability and responsiveness of the proposed control method.

- The proposed HVDC system model, implemented using MATLAB, was verified by comparisons with the comprehensive PSCAD model of a real operating HVDC system. The proposed model can be substituted for the PSCAD model and used to analyze the dynamic operation of the HVDC system under normal (i.e., no-fault) conditions, significantly reducing the computational time.

Section II presents the state space model of the LCC HVDC system with the proposed control scheme. The root locus analyses are presented in Section III. Section IV discusses the simulation case studies for the step and continuous responses to DC power references. Section V provides conclusions.

\section{PROPOSED CONTROL OF AN LCC HVDC SYSTEM}

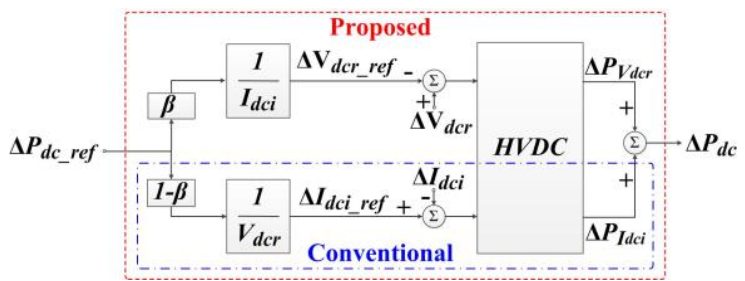

Fig. 1. A simplified schematic diagram of the proposed and conventional control methods for an LCC HVDC system.

Fig. 1 shows a simplified schematic diagram of the proposed and conventional control methods for an LCC HVDC system. The conventional HVDC system regulates the DC current $\Delta I_{d c i}$ at the inverter side to transfer the DC power $\Delta P_{d c}$ from the rectifier to the inverter. The DC voltage at the rectifier side $V_{d c r}$ remains almost constant: i.e., $\Delta I_{d c i}$ is almost linearly proportional to $\Delta P_{d c}$. In contrast, the proposed HVDC system regulates both $\Delta I_{d c i}$ and $\Delta V_{d c r}$ for a faster transient response and a larger short-term operating margin of $\Delta P_{d c}$ than in the conventional method. In Fig. $1, \beta$ is pre-defined as a participation factor, affecting the current and voltage references $\Delta I_{d c i_{-} r e f}$ and $\Delta V_{d c r_{-} r e f}$ at the inverter and rectifier, respectively. Note that $\Delta V_{d c_{-} r e f}$ is estimated using the values of $\Delta P_{d c_{-} r e f}$ and $I_{d c i}$, which are measured at the inverter and delivered to the rectifier via a communications system with a time delay.

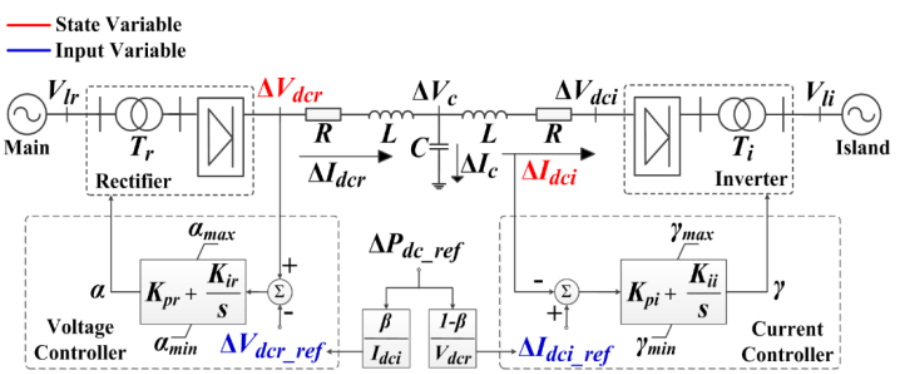

Fig. 2. Proposed control method for an LCC HVDC system with the state and input variables used to develop the state space model.

Fig. 2 presents a configuration of the proposed control scheme where the rectifier operates under voltage control and the inverter operates under current control. The firing angle $\alpha$ and extinction angle $\gamma$ are both regulated by the PI controllers, whose input variables are defined as the difference between $\Delta V_{d c_{-} r e f}$ and $\Delta V_{d c r}$ and between $\Delta I_{d c_{-} r e f}$ and $\Delta I_{d c i}$, respectively. The DC line is represented by a T-model, which has three dynamic state variables: $\Delta I_{d c i}$, the DC current $\Delta I_{d c r}$ at the rectifier, and the DC voltage $\Delta V_{c}$ at the middle of the DC line. The dynamic variables are represented as functions of $\Delta V_{d c r}$ and $\Delta I_{d c i}$, as will be discussed in Section II-A, to develop the state space model of the HVDC system using the proposed control scheme. Therefore, only $\Delta V_{d c r}$ and $\Delta I_{d c i}$ are set as the state variables, allowing direct calculation of $\Delta P_{d c}$ for the input variables $\Delta V_{d c r_{-} r e f}$ and $\Delta I_{d c c_{-} r e f}$. In other words, the state space model becomes intuitive and hence easily applicable to conventional grid operators or HVDC system operators.

\section{A. State Space Model for the Proposed Control Method}

In Figs. 1 and 2, $\Delta P_{d c}$ can be calculated using $\Delta V_{d c r}$ and $\Delta I_{d c i}$ : 


$$
\Delta P_{d c}=\Delta P_{I d c i}+\Delta P_{V d c r}=V_{d c r 0} \Delta I_{d c i}+I_{d c i 0} \Delta V_{d c r} .
$$

In (1), $\Delta V_{d c r}$ and $\Delta I_{d c i}$ can be obtained from (2) and (3), which are derived from the equations for $V_{d c r}$ and $V_{d c i}[22]$.

$$
\begin{aligned}
\Delta V_{d c r} & =\left(-\frac{3 \sqrt{2} B_{r} \cos \left(\frac{\mu_{r}}{2}\right)}{\pi T_{r} \sin ^{2}\left(\alpha+\frac{\mu_{r}}{2}\right)}\right) I_{d c r 0} \Delta \alpha+\left(\frac{3 \sqrt{2} B_{r} \cos \alpha}{\pi T_{r} \sin \left(\alpha+\frac{\mu_{r}}{2}\right)}-\frac{3 X_{c r} B_{r}}{\pi}\right) \Delta I_{d c r} \\
& =M_{1 r} \Delta \alpha+M_{2 r} \Delta I_{d c r} \\
\Delta V_{d c i} & =\left(-\frac{3 \sqrt{2} B_{i} \cos \left(\frac{\mu_{i}}{2}\right)}{\pi T_{i} \sin ^{2}\left(\gamma+\frac{\mu_{i}}{2}\right)}\right) I_{d c i 0} \Delta \gamma+\left(\frac{3 \sqrt{2} B_{i} \cos \gamma}{\pi T_{i} \sin \left(\gamma+\frac{\mu_{i}}{2}\right)}-\frac{3 X_{c i} B_{i}}{\pi}\right) \Delta I_{d c i} \\
& =M_{1 i} \Delta \gamma+M_{2 i} \Delta I_{d c i}
\end{aligned}
$$

Note that $\Delta \alpha$ and $\Delta \gamma$ in (2) and (3), respectively, are functions of the state variables $\Delta V_{d c r}$ and $\Delta I_{d c i}$ and the input variables $\Delta V_{d c_{-} r e f}$ and $\Delta I_{d c_{-} r e f}$, as shown in Fig. 2. Fig. 2 also shows that $\Delta I_{d c r}$ and $\Delta V_{d c i}$ in (2) and (3) can be calculated using $\Delta V_{d c r}$ and $\Delta I_{d c i}$ of the DC line. Using the equations for $\Delta \alpha, \Delta \gamma, \Delta I_{d c r}$, and $\Delta V_{d c i}$ provided in Appendix A, (2) and (3) can be converted to (4) and (5), which are expressed in the frequency domain $s$.

By using additional equations to express the differentials of $H, Y, U$, and $Z$ (see Appendix B), (4) and (5) can be divided into multiple first-order differential equations, which are in a matrix form as:

$$
[A][\dot{X}]+[B][X]=[C] \cdot u_{\text {input }} .
$$

This procedure is comprehensively explained in Appendix B. From (6), the state space model of the LCC HVDC system with the proposed control method is represented by:

where

$$
[\dot{X}]=[A]_{i n v}(-[B])[X]+[A]_{i n v}[C] \cdot u_{\text {input }},
$$

$$
\begin{gathered}
{[X]=\left[\begin{array}{cccccccccccc}
H & \cdots & H^{(3)} & Y & \cdots & Y^{(3)} & U & \cdots & U^{(3)} & Z & \cdots & Z^{(3)}
\end{array}\right]^{T},} \\
{[C] \cdot u_{\text {input }}=\left[\begin{array}{lllll}
c_{4} U & r_{4} Z & {[0]_{1 \times 12}}
\end{array}\right]^{T} .}
\end{gathered}
$$

The matrix coefficients of the state space model in (7)-(9) are provided in Appendix B. Note that (7)-(9) include the DC line model and the converter models of the HVDC system. For simplicity, phase-looked loops were not considered in this paper, because they have a negligible effect on the dynamics of the HVDC system [16], [20].

\section{B. Short-Term Operating Margin of DC Power Transfer}

The proposed control scheme increases the short-term operating margin of DC power transfer from the rectifier to the inverter, compared to the conventional scheme where $V_{d c r}$ is maintained as almost constant. As shown in (1), $\Delta P_{d c}$ is equal to $V_{d c o} \cdot \Delta I_{d c i}$ in the conventional method, whereas it is represented with an additional term $I_{d c} \cdot \Delta V_{d c r}$ or, equivalently, $\Delta P_{V d c r}$, in the proposed method. Specifically, the maximum value of $\Delta V_{d c r}$ is equal to the difference between the maximum DC voltage at the rectifier side (i.e., $V_{d c r_{-} \max }$ ) and the present state value (i.e., $\left.V_{d c r}\right)$, as shown in (10), under the condition that the tap changer does not operate.

$$
\max \left(\Delta V_{d c r}\right)=V_{d c r_{-} \max }-V_{d c r 0}
$$

In (10), $V_{d c_{-} \text {max }}$ can be obtained by substituting $\alpha_{\min }$ for $\alpha$ in (15), as discussed in Appendix A, which results in the maximum value of $\Delta P_{V d c r}$ being:

$$
\max \left(\Delta P_{V d c r}\right)=I_{d c i 0}\left(\frac{\frac{3 \sqrt{2} B_{r}}{\pi T_{r}} V_{l r} \cos \left(\alpha_{\min }\right)-\frac{3 X_{c r} B_{r}}{2 \pi R} V_{d c r 0}}{1+\frac{3 X_{c r} B_{r}}{2 \pi R}}-V_{d c r 0}\right) \text {. }
$$

Using (11), the maximum participation factor $\beta_{\max }$ can be estimated to be

$$
\beta_{\max }=\frac{\max \left(\Delta P_{V d c r}\right)}{P_{\text {rated }}-P_{0}+\max \left(\Delta P_{V d c r}\right)},
$$

where $P_{o}$ and $P_{\text {rated }}$ are the operating and rated power inputs to the HVDC system.

For example, the maximum value of $\Delta P_{d c}$ in the conventional control scheme is $75 \mathrm{MW}$ for the Jeju-Haenam HVDC system, under the normal condition that the HVDC system operates at $50 \%$ of the $150-\mathrm{MW}$ rated capacity (i.e., 75 MW) [23]. Considering the operating margin, $\alpha_{\min }$ and $\alpha$ are set to $5^{\circ}$ and $15^{\circ}$, respectively, resulting in $\beta_{\max }=0.07$. In the proposed scheme, it can transmit an additional 5.6 MW (i.e., $7.4 \%$ of $75 \mathrm{MW}$ ) on top of $75 \mathrm{MW}$ by simply regulating the DC voltage, which is high enough to support $56 \%$ of the peak load demand of Jeju International Airport. It follows that for real-time grid frequency regulation, the proposed control scheme allows the HVDC system to respond to higher DC power references than the conventional scheme. Specifically, in the conventional scheme, the DC current and power references are normally restricted up to the rated values (i.e., $1.0 \mathrm{pu}$ ) [24], [25]. In contrast, the proposed control scheme enables a temporary increase in the DC voltage and consequently in DC power for a short time period when the HVDC system receives a DC power reference higher than the rated capacity of the HVDC system. In practice, this often happens to energy resources participating in real-time frequency regulation [26]. Note that the temporary increase in the DC voltage can be

$$
\begin{aligned}
& H\left\{s^{3}\left(-L C K_{p r} M_{1 r}\right)+s^{2}\left(L C-M_{1 r}\left(R C K_{p r}+L C K_{i r}\right)\right)+s\left(R C-M_{1 r}\left(K_{p r}+R C K_{i r}\right)-M_{2 r} C\right)+1-M_{1 r} K_{i r}\right\} \\
& =Y\left(M_{2 r}\right)-U\left\{s^{3}\left(L C K_{p r} M_{1 r}\right)+s^{2}\left(M_{1 r}\left(R C K_{p r}+L C K_{i r}\right)\right)+s\left(M_{1 r}\left(K_{p r}+R C K_{i r}\right)\right)+M_{1 r} K_{i r}\right\} \\
& H-Y\left\{s^{3}\left(L^{2} C-M_{1 i} K_{p i} L C\right)+s^{2}\left(2 R L C-M_{1 i}\left(R C K_{p i}+L C K_{i i}\right)+L C M_{2 i}\right)+s\left(R^{2} C+2 L-M_{1 i}\left(K_{p i}+R C K_{i i}\right)+M_{2 i} R C\right)+2 R-M_{1 i} K_{i i}+M_{2 i}\right\} \\
& =Z\left\{s^{3}\left(L C K_{p i} M_{1 i}\right)+s^{2}\left(M_{1 i}\left(R C K_{p i}+L C K_{i i}\right)\right)+s\left(M_{1 r}\left(K_{p i}+R C K_{i i}\right)\right)+M_{1 i} K_{i i}\right\} \\
& \text { where } H=\Delta V_{d c r}, \quad Y=\Delta I_{d c i}, \quad U=\Delta V_{d c r_{-} r e f}, \quad Z=\Delta I_{d c i \_r e f}
\end{aligned}
$$


achieved without operating the tap changers in the converter transformer, which takes more time than required for real-time frequency control. The proposed method can immediately increase the operating margin of DC power transfer and therefore is beneficial to the power grid, particularly where LCC HVDC systems participate in frequency regulation.

\section{Root Locus Analysis of THE State SPace Model}

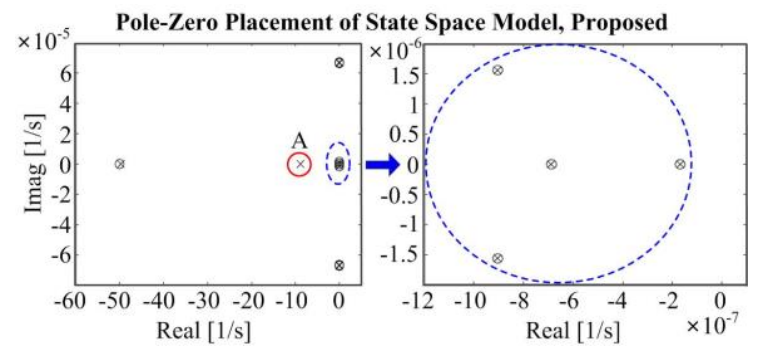

Fig. 3. Pole-zero placements of the HVDC system using the proposed method for $L=0.2[\mathrm{H}],\left(K_{p r}, K_{p i}\right)=\left(2.0 \times 10^{-3}, 5.5 \times 10^{-3}\right)$, and $\left(K_{i r}, K_{i i}\right)=(5,0.35)$.

Fig. 3 shows the pole-zero placements of the HVDC system model, developed in Section II-A, for the proposed control scheme. The DC line inductance $L$ and converter controller gains $\left(K_{p r}, K_{p i}\right)$ and $\left(K_{i r}, K_{i i}\right)$ are set to $0.2 \mathrm{H},\left(2.0 \times 10^{-3}\right.$, $\left.5.5 \times 10^{-3}\right)$, and $(5,0.35)$, respectively. The state space model in (7)-(9) has 22 poles and 21 zeros in total for the proposed scheme. As shown in Fig. 3, the poles are located close to the zeros, apart from the one placed at point ' $\mathrm{A}$ '; this is the dominant pole. All the poles are placed on the left-hand half plane, implying that the proposed control method ensures stable operation of an LCC HVDC system.

(a)

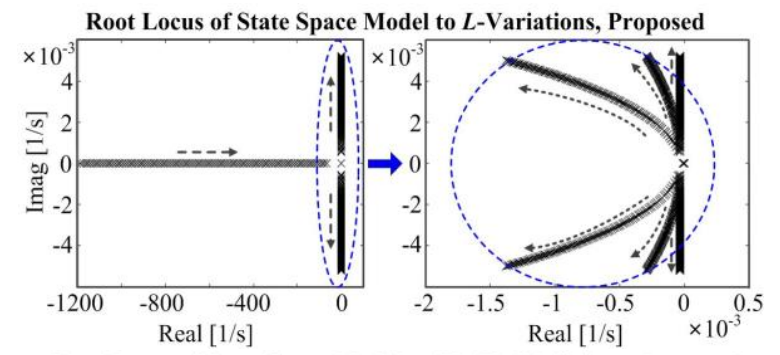

Root Locus of State Space Model to $K p r, K p i$-Variations, Proposed

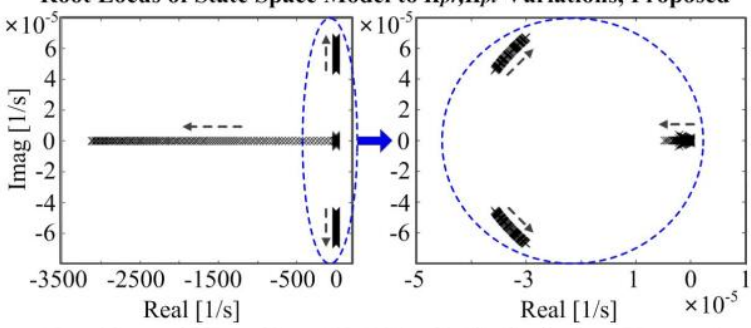

Root Locus of State Space Model to Kir,Kii-Variations, Proposed
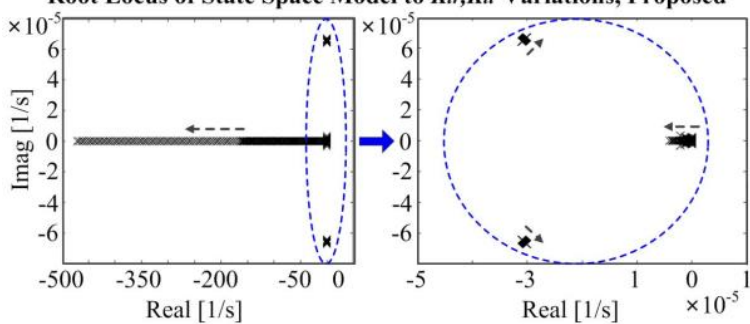

Fig. 4. Eigenvalue locations for the proposed method with (a) $L$ increasing from $2.7 \times 10^{-3} \mathrm{H}$ to $5.4 \times 10^{-1} \mathrm{H}$; (b) $\left(K_{p r}, K_{p i}\right)$ increasing from $\left(0.5 \times 10^{-3}, 1.5 \times 10^{-3}\right)$ to $(0.1,0.1)$; and (c) $\left(K_{i r}, K_{i i}\right)$ increasing from $\left(2.0,0.5 \times 10^{-1}\right)$ to $\left(1.0 \times 10^{2}, 5.0\right)$.
Root locus analyses of the state space model have been performed to investigate the effects of the variations in $L,\left(K_{p r}\right.$, $\left.K_{p i}\right)$, and $\left(K_{i r}, K_{i i}\right)$ on the stability and responsiveness of the LCC HVDC system using the proposed control method. Its stable operation is guaranteed over a wide range of values for $L$, $\left(K_{p r}, K_{p i}\right)$, and $\left(K_{i r}, K_{i i}\right)$. Specifically, in Fig. $4, L,\left(K_{p r}, K_{p i}\right)$, and $\left(K_{i r}, K_{i i}\right)$ increased from $2.7 \times 10^{-3} \mathrm{H}$ to $5.4 \times 10^{-1} \mathrm{H}$, from $\left(5.0 \times 10^{-4}, 1.5 \times 10^{-3}\right)$ to $(0.1,0.1)$, and from $\left(2.0,5.0 \times 10^{-2}\right)$ to $\left(1.0 \times 10^{2}, 5.0\right)$, respectively. These maximum and minimum limits of the converter controller gains were determined based on previous studies [27]-[29], while ensuring the stabilized variation in $V_{d c r}$ and $I_{d c i}$ for the full operating range of the converters. In [27]-[29], HVDC systems were modelled using the rated DC voltage and power similar to those of the test HVDC system in this paper: i.e., $V_{d c_{-} \text {rated }}=184 \mathrm{kV}$ and $P_{d c_{-} \text {rated }}$ $=150 \mathrm{MW}$. Note that optimizing the converter controller gains is beyond the scope of this paper.

Fig. 4(a) shows that as $L$ increases, the complex conjugate eigenvalues move in the positive and negative directions along with the imaginary axis, and the dominant real eigenvalue moves close to the imaginary axis. Therefore, as $L$ rises, the HVDC system slowly goes to a steady-state operating point with small-size, high-frequency oscillation, which is consistent with intuition. Additionally, Fig. 4(b) and (c) show that as converter controller gains increase, the dominant eigenvalue becomes significantly negative; i.e., the dynamic operation of the HVDC system is rapidly stabilized.

(a)

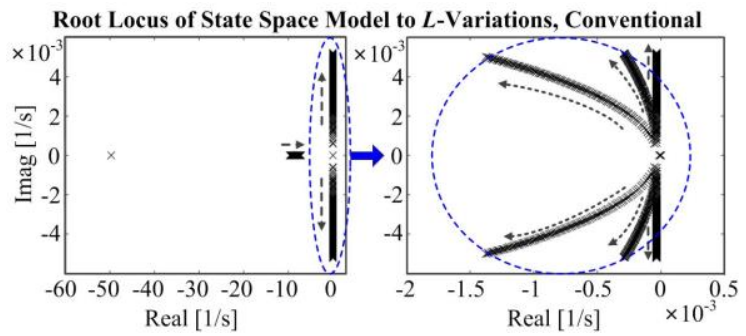

Root Locus of State Space Model to Kpi-Variations, Conventional

(b)

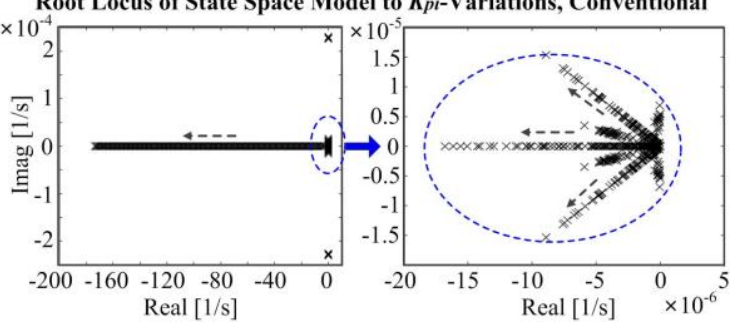

(c)

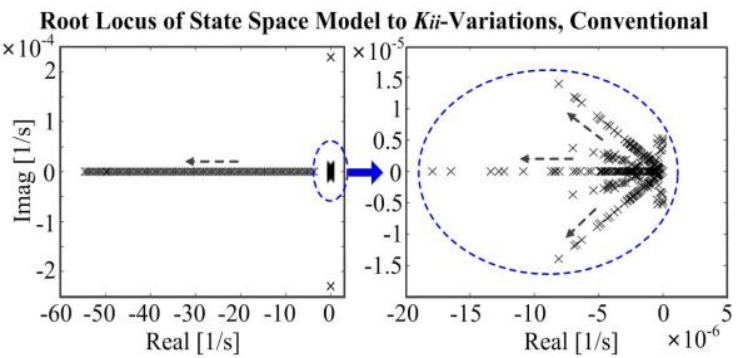

Fig. 5. Eigenvalue locations for the conventional method with the same range of values of (a) $L$, (b) $\left(K_{p r}, K_{p i}\right)$, and (c) $\left(K_{i r}, K_{i i}\right)$.

Analogously, Fig. 5 shows the eigenvalue locations of the LCC HVDC system for the conventional method (i.e., $\Delta V_{d c r_{-} r e f}$ $=0)$ for the same range of values of $L,\left(K_{p r}, K_{p i}\right)$, and $\left(K_{i r}, K_{i i}\right)$. 
Comparison of Figs. 4 and 5 reveals that the proposed control method enables the HVDC system to respond more rapidly to the reference signal given from the grid operator, compared to the conventional method. In other words, the dominant eigenvalue for the proposed method is more significantly negative than that for the conventional one. In Figs. 4(a) and 5 (a), the dominant poles start moving from the positions $s=$ -1186.7 and -9.7 for the proposed and conventional methods, respectively. In Fig. 4(b) and (c), the poles move to the positions $s=-3119.9$ and $s=-471.6$, respectively, whereas in Fig. 5(b) and (c), they stop at $s=-173.6$ and -54.8 , respectively. This finding implies the significant potential of the proposed HVDC control method for real-time frequency regulation, particularly in a power grid such as the Jeju Island network, where the flexibility provided by fast-responsive power equipment is necessary to compensate for large variations in output power of intermittent renewable generators. The proposed method can be easily applied to existing LCC HVDC systems by implementing an additional controller on the rectifier side; it does not require significant changes in the HVDC systems or their specifications.

\section{CAse Studies And Results}

\section{A. Test System and Simulation Conditions}

The state space model discussed in Sections II and III was implemented using MATLAB. It was then validated by comparison with a switch-level model, which was implemented using PSCAD/EMDC (or simply PSCAD) [30]. The HVDC converters and controllers were designed using thyristor valve models. Note that in [30], for simplicity the AC grids were represented using ideal voltage sources. The PSCAD model received only $\Delta I_{d c i}$ ref as the input signal for the regulation of $\Delta P_{d c}$; i.e., it operated using the conventional method where the $\mathrm{DC}$ voltage was maintained as constant at the rated value. The communication time delay $T_{c m}$ between the rectifier and inverter controllers was set to $0.03 \mathrm{~s}$ [31]; the effects of variations in $T_{c m}$ on the performance of the proposed method are analyzed in Section IV-B. Furthermore, Table I lists the parameters used for the state space model. Using these parameters, the transient DC voltage and current variation of the PSCAD model were validated by comparing them to the values acquired from a real HVDC system, particularly under AC line-to-ground fault conditions in [21]. The PSCAD model has been further developed for application of the proposed control method in this paper.

The Jeju-Haenam HVDC system in Korea was used as a test case, due to the accessibility of the required modeling parameters. Specifically, the HVDC system has a rated power

\begin{tabular}{l|ll|ll}
\multicolumn{4}{l}{ TABLE I. DETAILD PARAMETERS OF THE JEJU-HAENAM HVDC SYSTEM } \\
\hline & Parameters & Values & Parameters & Values \\
\hline \hline & $V_{d c r}[\mathrm{kV}]$ & 184 & $V d c i 0[\mathrm{kV}]$ & 183.5 \\
& $I_{d c r}, I_{d c i 0}[\mathrm{~A}]$ & 204 & $I_{c 0}[\mathrm{~A}]$ & 0 \\
& $B_{r}, B_{i}$ & 2 & $R[\Omega]$ & 1.116 \\
Parameters & $X_{c r}, X_{c r}[\Omega]$ & 7.99 & $L[\mathrm{H}]$ & 0.2 \\
for the state & $T r, T_{i}$ & 0.514 & $C[\mu \mathrm{F}]$ & 54 \\
space model & $V l r[\mathrm{kV}]$ & 75.9 & $V l i[\mathrm{kV}]$ & 82.2 \\
& $\alpha \min \left[{ }^{\circ}\right]$ & 5 & $\beta$ & 0.07 \\
& $K_{p r}$ & 0.002 & $K_{i r}$ & 5 \\
& $K_{p i}$ & 0.0055 & $K_{i i}$ & 0.35 \\
\hline
\end{tabular}

of $150 \mathrm{MW}$ and a rated DC voltage of $184 \mathrm{kV}$. An XLPE cable with a length of $100 \mathrm{~km}$ was used for the DC line [32]. Each of the HVDC system converters consists of a converter transformer, 12 valves including multiple thyristor stacks, and five controllers in addition to the proposed DC current and voltage controllers. Briefly, the five controllers regulate the firing and extinction angles to maintain practical operation of the HVDC system under the abnormal condition of the AC grid; the controllers do not directly improve the transient response or short-term power transfer capability of the system.

The inverter in the Jeju-Haenam HVDC system interfaces with a small islanded grid (i.e., the Jeju grid). A short circuit ratio (SCR) of the Jeju grid is 4.0. It compensates for network power imbalances in the islanded grid by receiving DC power a rectifier bus on the Korean mainland grid. The power imbalances are caused mainly by the large penetration of wind turbines and small reserve capacity of steam turbine generators. Conventionally, the Jeju grid operator estimates the DC power reference required to maintain the real-time power balance, and controls the inverter current directly, instead of sending the reference to the rectifier controller via the communications system. In other words, the rectifier bus acts as an infinite bus from the perspective of the inverter bus, which works as a time-varying sink load. There is another type of HVDC system where the inverter is responsible for DC voltage regulation and the rectifier responds to a time-varying DC current reference. This control scheme is more common. Therefore, this paper considers the two types of LCC HVDC system (i.e., the test type (Type I) and the common type (Type II)) for the analysis of grid frequency regulation. The Jeju-Haenam HVDC system is described in more detail in [30].

In Section IV-B, the step responses of the state space model were analyzed for the conventional and proposed methods with a time delay $T_{c m}$. The step responses for both methods were verified by comparison with those of the PSCAD models. The step responses of the state space models are also compared in Section IV-C for various values of the DC line parameters (i.e., $L$ and $C$ ) to demonstrate the wide applicability of the proposed method. Table II lists the maximum and minimum values of $L$ and $C$ that have been reported in [33]-[35]. Section IV-D shows the responses to continuous time-varying signals $P_{d c_{-} r e f}$ for 20 seconds, which were modified from the Reg-D signal of PJM [36]. Section IV-E shows the effects of the proposed method on real-time frequency regulation in an islanded AC grid for both types of HVDC system (i.e., Types I and II).

\begin{tabular}{c|cc|cc}
\multicolumn{2}{c}{ TABLE II. RANGES OF THE DC Line Parameter VALUES IN [33]-[35] } \\
\hline & \multicolumn{2}{|c|}{ Minimum } & \multicolumn{2}{c}{ Maximum } \\
& {$[\mathrm{pu}]$} & {$[\mathrm{H}] /[\mu \mathrm{F}]$} & {$[\mathrm{pu}]$} & {$[\mathrm{H}] /[\mu \mathrm{F}]$} \\
\hline$L$ & $0.96 \times 10^{-2}$ & 0.0027 & $190 \times 10^{-2}$ & 0.54 \\
$C$ & $1.8 \times 10^{3}$ & 6.5 & $38 \times 10^{3}$ & 133.7 \\
\hline
\end{tabular}

\section{B. Comparisons of Step Responses for Control Methods}

Fig. 6(a)-(c) compare the step responses of $P_{d c}, I_{d c i}$, and $V_{d c r}$, respectively, for the state space models using the proposed and conventional methods, as well as those of the PSCAD models, to $\Delta P_{d c_{-} r e f}\left(t=0.1^{+}\right)=0.5 \mathrm{pu}$. The time delay $T_{c m}$ was set to 0.03 s. Note that "SS" in Fig. 6 stands for the "state space"; for example, "SS_Conventional" and "SS_Proposed" are the state 
space models of the HVDC system using the conventional and proposed schemes, respectively.

Fig. 6(a) shows that for the conventional method, the state space model in (7)-(9) for the Jeju-Haenam HVDC system has almost the same step response as that of the PSCAD model to $\Delta P_{d c_{-} \text {ref }}\left(t=0.1^{+}\right)=0.5$ pu. Furthermore, Fig. 6(b) shows that in per-unit values, $I_{d c i}$ ref and $I_{d c i}$ are the same as $P_{d c_{-} \text {ref }}$ and $P_{d c}$, respectively, because $V_{d c r}$ is almost constant at $1.0 \mathrm{pu}$ (see Fig. 6(c)) for the conventional method. However, for the proposed method, $I_{d c_{-} r e f}$ increased to $0.95 \mathrm{pu}$, because $\Delta P_{d c_{-} r e f}$ was divided into two parts (i.e., $\beta \cdot \Delta P_{d c_{-} r e f}$ and $(1-\beta) \cdot \Delta P_{d c_{-} r e f}$ ). For the proposed method, $I_{d c i}$ also successfully followed $I_{d c i}$ ref, as shown in Fig. 6(b). Fig. 6(c) shows that for the proposed method with $\beta=0.1, V_{d c r_{-} \text {ref }}$ increased to 1.05 pu and $V_{d c r}$ was adjusted to successfully follow $V_{d c r_{-} \text {ref }}$ within $0.1 \mathrm{~s}$.

As shown in Fig. 6(a), the step response is faster when the proposed method is used instead of the conventional method. This is because for the proposed method, $P_{d c}$ is affected by not only $\Delta I_{d c i}$ but also $\Delta V_{d c}$, which changes very rapidly, as shown in Fig. 6(c), by controlling the firing angle $\alpha$ at the converter station. In addition, Fig. 6(b) shows that $\Delta I_{d c i}$ for the proposed method also has a faster response than that for the conventional one. This is mainly because $\Delta I_{d c i}$ is a function of $\Delta V_{d c r}$, as shown in (5) and equivalently in (13):

$\Delta I_{d c i}=\frac{1}{\left(q_{1} s^{3}+q_{2} s^{2}+q_{3} s+q_{4}\right)} \Delta V_{d c r}+\frac{\left(r_{1} s^{3}+r_{2} s^{2}+r_{3} s+r_{4}\right)}{\left(q_{1} s^{3}+q_{2} s^{2}+q_{3} s+q_{4}\right)} \Delta I_{d c i-r e f}$,

where $q_{1-4}$ and $r_{1-4}$ have positive values that can be adjusted using the PI gains $\left(K_{p i}, K_{i i}\right)$. In other words, for the proposed method, $\Delta I_{d c i}$ can change with the two terms $\Delta V_{d c r}$ and $\Delta I_{d c i_{-} r e f}$,

(a)
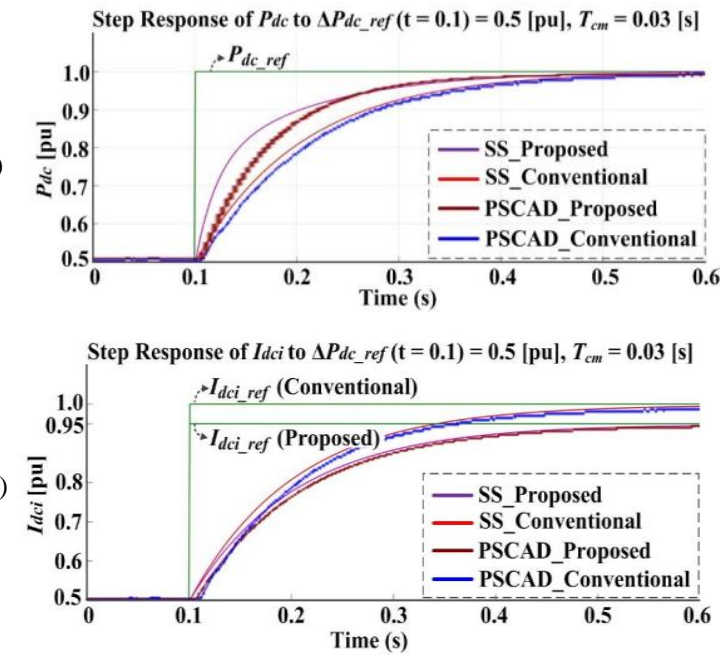

(c)

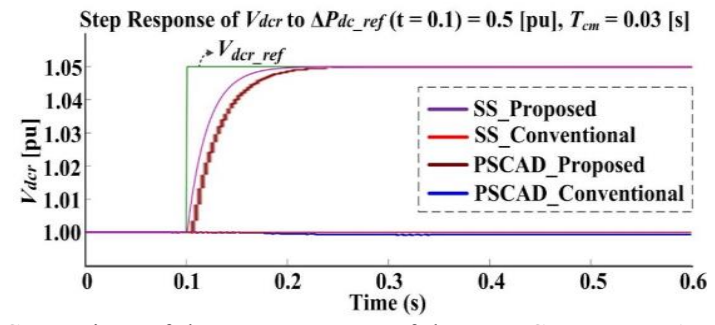

Fig. 6 Comparison of the step responses of the HVDC system to $\Delta P_{d c \text { ref }}(t=$ $\left.0.1^{+}\right)=0.5$ pu for the proposed and conventional control methods: (a) $P_{d c}$, (b) $I_{d c i}$, and (c) $V_{d c r}$. For both methods, the step responses of the state-space and PSCAD models are also compared. whereas for the conventional method, it is affected only by $\Delta I_{d c i_{-} r e f}$. The additional term regarding $\Delta V_{d c r}$ and consequently $\Delta V_{d r_{-} \text {ref }}$ leads to a faster response of $\Delta I_{d c i}$. Furthermore, in the conventional method, $I_{d c i}$ flows via the DC line due to the difference between the DC voltages at both converter sides. The line inductance $L$ prevents $I_{d c i}$ from instantaneously changing to $I_{d c i}$ ref, as discussed in Section III.

In Fig. 6, the step responses of the proposed state-space models are very similar to those of the PSCAD models. There are slight differences: i.e., in the case of the PSCAD models, $P_{d c}, I_{d c i}$, and $V_{d c r}$ increased after a short-time delay and increased slightly slower for the initial period of the transient time than those for the state space models. This is mainly attributed to the implementation of the valve and firing controllers in the PSCAD model, which were omitted from the state space model (7)-(9) for simplicity.

The communication time delays in wide-area power system range from tens to hundreds of milliseconds [37]. Fig. 7 shows the step responses of the proposed HVDC model as $T_{c m}$ increases from $0 \mathrm{~s}$ to $0.5 \mathrm{~s}$. The proposed HVDC system can still respond faster to the reference signal than the conventional HVDC system. Note that for $T_{c m}=0.5 \mathrm{~s}, P_{d c}$ approaches the steady state value slowly after approximately $t=0.37 \mathrm{~s}$; however, this has a minor influence on the real-time grid frequency regulation, as will be discussed in Section IV-E.

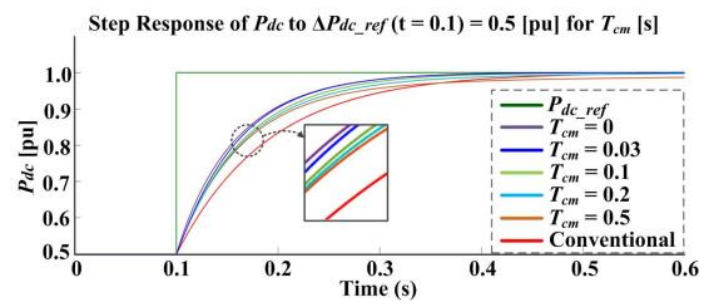

Fig. 7. Step responses of the proposed method to $\Delta P_{d c_{-} \text {ref }}(t=0.1)=0.5 \mathrm{pu}$ for various time delays $T_{c m}$.

C. Comparisons of Step Responses for DC Line Parameters
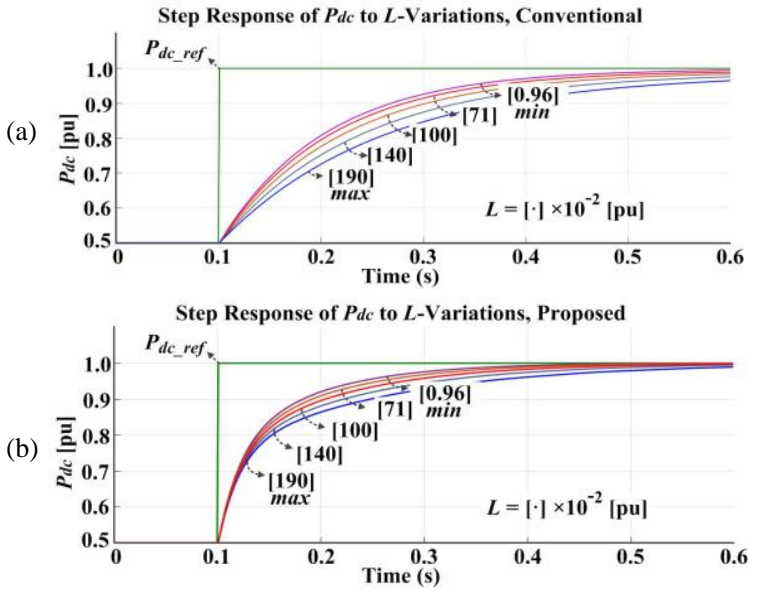

Fig. 8. Step responses calculated using the (a) conventional and (b) proposed methods when $\Delta P_{d c_{-} r e f}(t=0.1)=0.5 \mathrm{pu}$ as a function of $L$ of the DC line.

Fig. 8(a) shows the step responses of the LCC HVDC system for the conventional method. The values of $L$ for the DC line increased from $0.96 \times 10^{-2}$ pu to $190 \times 10^{-2}$ pu. As shown in Fig. 8(a), the rate at which $P_{d c}$ approached $P_{d c_{-} r e f}$ decreased as $L$ increased. This is mainly because the line inductance impedes 
the change in $I_{d c}$, which is proportional to $P_{d c}$ for the conventional method. Fig. 8(b) shows that the proposed method enabled the HVDC system to respond faster for all values of $L$, compared to the conventional one, although the time it took for $P_{d c}$ to reach $P_{d c_{-} r e f}$ gradually increased as $L$ increased. This implies that LCC HVDC systems can be effectively utilized to provide fast-responsive services for grid frequency regulation.

\section{Responses to Continuous Time-Varying Reference}

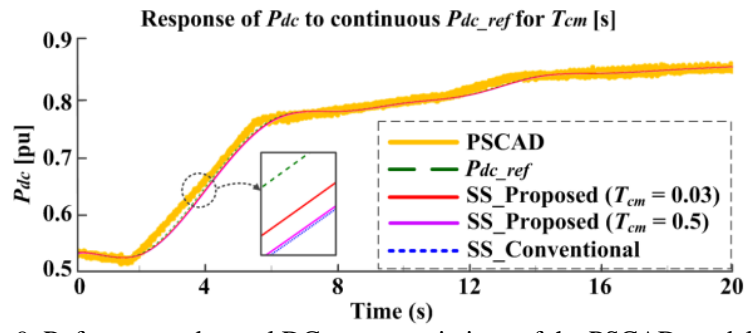

Fig. 9. Reference and actual DC power variations of the PSCAD model and the state-space model estimated using the proposed and conventional methods.

Fig. 9 shows the continuous time-varying DC power reference and the corresponding variations in the DC power of the state-space model for the conventional and proposed methods, as well as of the PSCAD model, during a time period of 20 seconds. It is clear that, in the case of the proposed method, $P_{d c}$ successfully followed $P_{d c_{-} \text {ref }}$ for $T_{c m}=0.03 \mathrm{~s}$ and $0.5 \mathrm{~s}$. In addition, the $P_{d c}$ curves were very similar to those of the PSCAD model. The state space model has sufficient capability to substitute for the PSCAD model when analyzing the dynamic response to the time-varying reference $P_{d c_{-} r e f}$, and allows a much faster processing time. To run the 20 -second simulation, it took only 62 seconds for the state space model, compared to 5276 seconds for the PSCAD model.

(a)

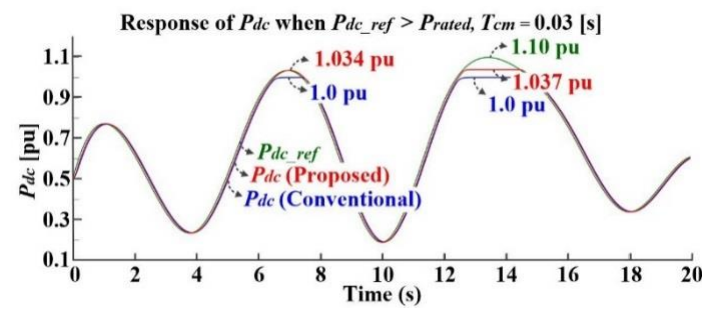

(b)

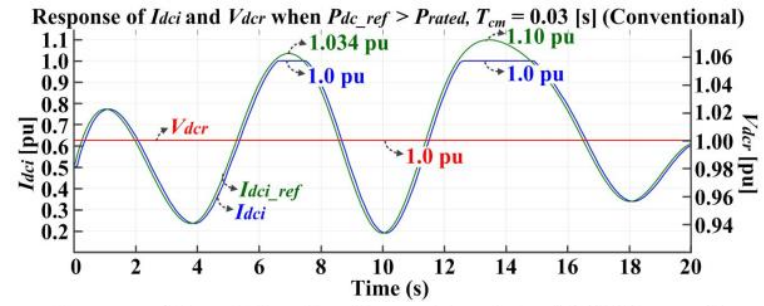

(c)

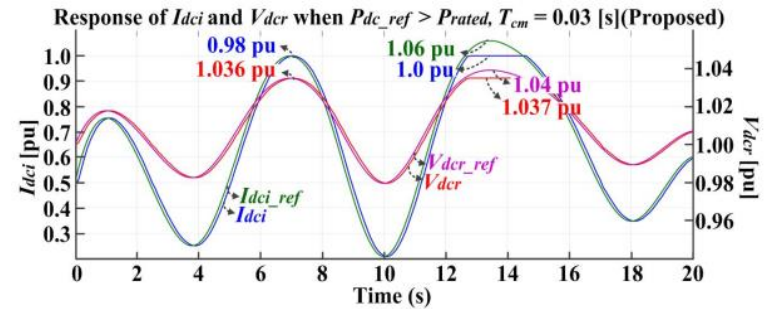

Fig. 10. Responses of the (a) DC power and (b), (c) DC current and voltage for the conventional and proposed methods, respectively, when the reference DC power is larger than the rated DC power.
The proposed control method has the capability to increase the operating margin of the DC power transfer for a short period of time. Fig. 10 shows the DC power, current, and voltage for both control schemes over 20 seconds. For this time period, it was assumed that $P_{d c_{-} r e f}$ happened to exceed the rated amount of DC power that can be transferred via the HVDC system using the conventional method. Specifically, $P_{d c_{-} r e f}$ was 1.034 $\mathrm{pu}$ and $1.10 \mathrm{pu}$ at $t=7 \mathrm{~s}$ and $13 \mathrm{~s}$, respectively. For the conventional method, $P_{d c}$ increased up to the rated value (i.e., $1.0 \mathrm{pu})$ at $t=7 \mathrm{~s}$ and $13 \mathrm{~s}$. In contrast, the proposed method, where $V_{d c r}$ was additionally controlled, allowed a temporary increase in the maximum DC power to be transferred. As shown in Fig. 10(a), $P_{d c}$ increased to 1.034 pu and 1.037 pu at $t$ $=7 \mathrm{~s}$ and $13 \mathrm{~s}$, respectively. In Fig. 10(b), $V_{d c r}$ was maintained almost constant, whereas in Fig. 10(c), $V_{d c r}$ went up and down in synchrony with $I_{d c i} ; V_{d c r}$ increased to $1.036 \mathrm{pu}$ and $1.037 \mathrm{pu}$ at $t=7 \mathrm{~s}$ and $13 \mathrm{~s}$, respectively, where $I_{d c i}$ increased to $0.98 \mathrm{pu}$ and was limited to $1.0 \mathrm{pu}$, respectively. The maximum power that can be additionally transferred via the Jeju-Haenam HVDC system by regulating $V_{d c r}$ was 0.037 pu (i.e., 5.6 MW), as discussed in Section II-B.

Fig. 11 shows that for $T_{c m}=0.5 \mathrm{~s}, P_{d c}$ increased to $1.030 \mathrm{pu}$ and $1.037 \mathrm{pu}$ at $t=7 \mathrm{~s}$ and $13 \mathrm{~s}$, respectively. These were slightly less than the maximum values of $P_{d c}$ for $T_{c m}=0.03 \mathrm{~s}$. This implies that the communication time delay between the rectifier and inverter controllers does not have a significant effect on the maximum short-term DC power transfer capacity.

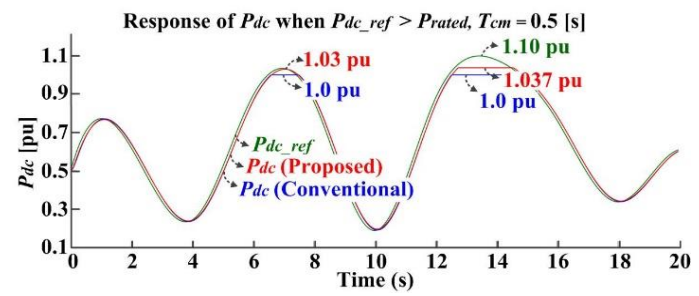

Fig. 11. Responses of the DC power for the proposed method with $T_{c m}=0.5 \mathrm{~s}$.

\section{E. Frequency Regulation using the Proposed HVDC System}

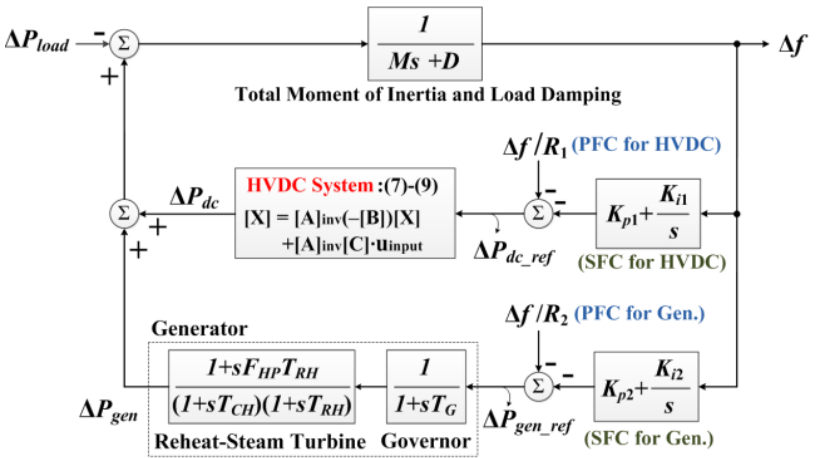

Fig. 12. Block diagram for analyzing the effect of the proposed HVDC system on the real-time grid frequency regulation in an isolated grid (i.e., the Jeju grid).

Fig. 12 shows a simplified block diagram describing frequency regulation in an isolated power grid (i.e., the $\mathrm{AC}$ grid on Jeju Island), including the HVDC system and the reheat steam turbine generator. The second-order transfer function can be used to represent the total accumulated dynamic response of reheat-steam turbine generators in the $\mathrm{AC}$ grid [22]. The following conditions were assumed in the analysis: 
- The frequency is controlled by adjusting the power generation and transmission of the generator and HVDC system, according to the reference signals $\Delta P_{\text {gen_ref }}$ and $\Delta P_{d c_{-} r e f}$, respectively.

- The reference signals consist of two components: i.e., the primary frequency control (PFC) and secondary frequency control (SFC). The PFC signals are produced using $\mathrm{P}$ controllers located where the individual units are connected to the grid. The SFC signals are generated centrally and distributed by the grid operator through communications links. PI controllers are commonly used for SFC [38].

- Table III shows the parameters used in the block diagram [22], [39]; the gains of the PFC and SFC were determined based on [40] and then tuned according to the results of the case study.

TABLE III. PARAMETERS FOR THE ANALYSIS OF FREQUENCY REGULATION

\begin{tabular}{c|cc|c|cc}
\hline Model & Parameter & Value & Model & Parameter & Value \\
\hline \hline \multirow{2}{*}{ AC Grid } & $M$ & 7 & \multirow{2}{*}{ PFC } & $R_{1}$ & 0.02 \\
& $D$ & 2 & & $R_{2}$ & 0.04 \\
\hline \multirow{3}{*}{ Generator } & $F_{H P}$ & 0.3 & & $K_{p 1}$ & 50 \\
& $T_{C H}$ & 0.3 & \multirow{2}{*}{$\mathrm{SFC}$} & $K_{i 1}$ & 20 \\
& $T_{R H}$ & 1.0 & & $K_{p 2}$ & 25 \\
& $T_{G}$ & 0.2 & & $K_{i 2}$ & 10 \\
\hline
\end{tabular}

(a)

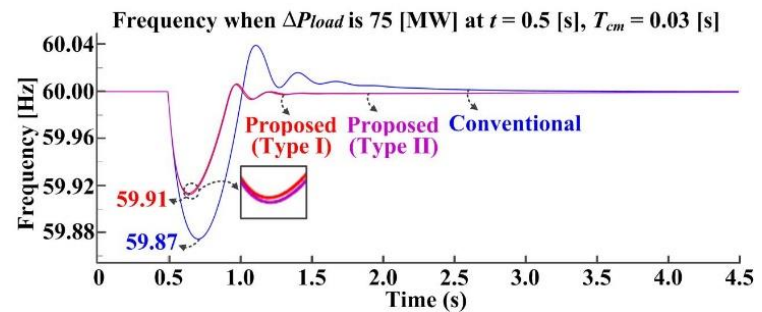

$P d c$ when $\Delta$ Pload is $75[\mathrm{MW}]$ at $t=0.5[\mathrm{~s}], T_{c m}=0.03[\mathrm{~s}]$

(b)
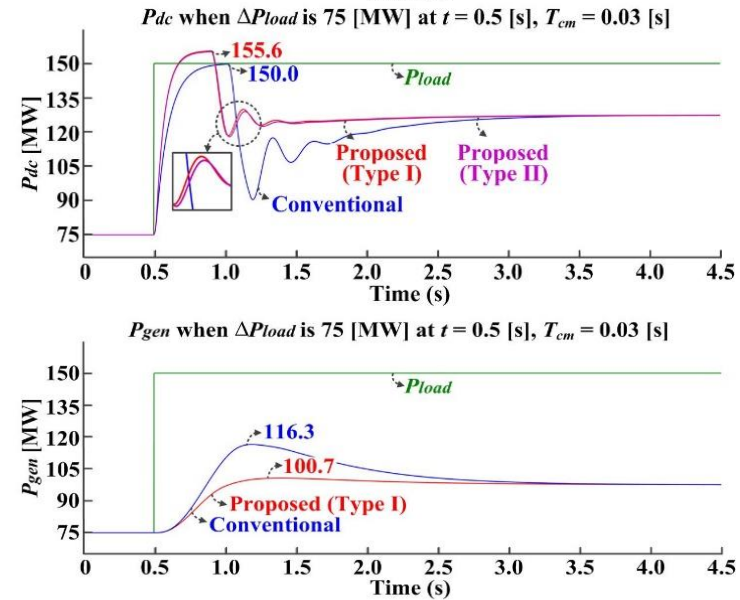

Fig. 13. (a) $\Delta f$, (b) $\Delta P_{d c}$, and (c) $\Delta P_{g e n}$ for the conventional and proposed HVDC system control methods with $T_{c m}=0.03 \mathrm{~s}$

Fig. 13 shows the variation in the grid frequency $f$, as well as in the power transmission $P_{d c}$ and generation $P_{g e n}$ of the HVDC system and the generator, when the load demand $P_{\text {load }}$ increased from $75 \mathrm{MW}$ to $150 \mathrm{MW}$ at $t=0.5 \mathrm{~s}$. Specifically, Fig. 13(a) shows that for the proposed method, $f$ decreased from $60 \mathrm{~Hz}$ to $59.91 \mathrm{~Hz}$ at $t=0.65 \mathrm{~s}$, whereas for the conventional method, it was reduced to $59.87 \mathrm{~Hz}$ at $t=0.71 \mathrm{~s}$. Furthermore, the frequency overshot less when it returned to $60 \mathrm{~Hz}$ for the proposed method than for the conventional method. This is because the HVDC system controlled by the proposed method could transmit a larger amount of DC power within a shorter period of time, as shown in Fig. 13(b). The DC power of the proposed system increased from $75 \mathrm{MW}$ to $155.6 \mathrm{MW}$ at $t=$ $0.90 \mathrm{~s}$, whereas the maximum DC power of the conventional system was limited to $150 \mathrm{MW}$. The smaller $\Delta f$ due to the larger and faster $\Delta P_{d c}$ led to the decrease in the maximum value of $\Delta P_{g e n}$. In Fig. 13(c), the maximum $\Delta P_{g e n}$ for the proposed and conventional systems were equivalent to $25.7 \mathrm{MW}$ and 41.3 MW, respectively. This implies that the proposed method effectively mitigates the required reserve capacity, and consequently the operating cost of the generator. Note that in both control methods, the HVDC system has a faster response than the thermal generator, which is consistent with the observations discussed in [41]. The results of the simulation were similar when $T_{c m}=0.5 \mathrm{~s}$. As shown in Fig. 13, the profiles of $\Delta f$ and $\Delta P_{d c}$ for the Type-II HVDC system are similar to those for the Type-I system. For both types, $\Delta f$ was reduced when the proposed method was applied, which implies that the proposed method is effective and widely applicable.

The participation of the HVDC system in frequency regulation was further investigated for continuous variation in the load demand. Specifically, Fig. 14 shows $P_{\text {load }}$ ranging from 59.16 MW to 94.24 MW. Fig. 15(a) and (b) compare $f$ and $P_{d c}$, respectively, for the conventional and proposed methods. For the proposed method, $f$ varied between $59.98 \mathrm{HZ}$ and $60.01 \mathrm{~Hz}$ during the simulation time period, whereas for the conventional method, it was reduced to $59.95 \mathrm{~Hz}$ and increased to $60.03 \mathrm{~Hz}$. This is because in the proposed method, the HVDC system could transmit a larger amount of DC power than in the conventional method, as shown in Fig. 15(b). With the proposed method, $P_{d c}$ was controlled in the range between 120 MW and 155.6 MW, whereas with the conventional method, the maximum value of $P_{d c}$ was limited to $150 \mathrm{MW}$. The smaller frequency deviation due to the larger and faster DC power transmission also led to the mitigation of $\Delta P_{\text {gen }}$; i.e., the difference between the maximum and minimum outputs of the generator was equivalent to $10.26 \mathrm{MW}$ and $23.03 \mathrm{MW}$ for the proposed and conventional methods, respectively, as shown in Fig. 15(c). For the results, the RMS variations in the grid frequency $\Delta f_{r m s}$ and the generator output power $\Delta P_{g e n, r m s}$ are estimated as:

$\Delta f_{r m s}=\sqrt{\frac{1}{N} \sum_{n=1}^{N}\left(f_{n}-f_{s s}\right)^{2}}$ and $\Delta P_{g e n, r m s}=\sqrt{\frac{1}{N} \sum_{n=1}^{N}\left(P_{g e n, n}-P_{g e n, s s}\right)^{2}}$,

where $n$ is the index of measurement samples and $N$ is the total number of samples. In addition, $f_{n}$ and $P_{\text {gen,ss }}$ are the $n_{\text {th }}$ sampled values of the grid frequency and generator output power, and $f_{s s}$ and $P_{g e n, s s}$ are their steady-state values, respectively. As summarized in Table IV, the proposed method enabled the HVDC system to effectively reduce $\Delta f_{r m s}$ and $\Delta P_{\text {gen, rms. }}$.

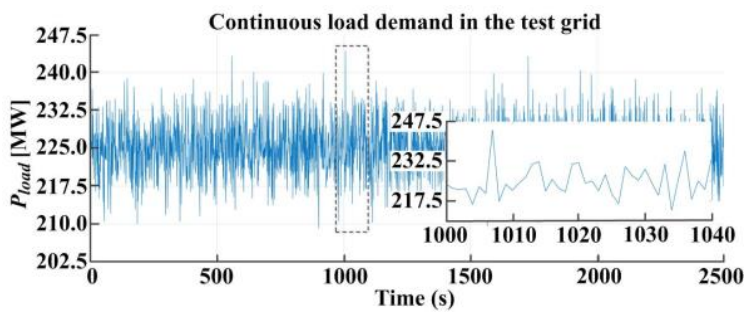

Fig. 14. Continuous load demand variations in the test system 
(a)

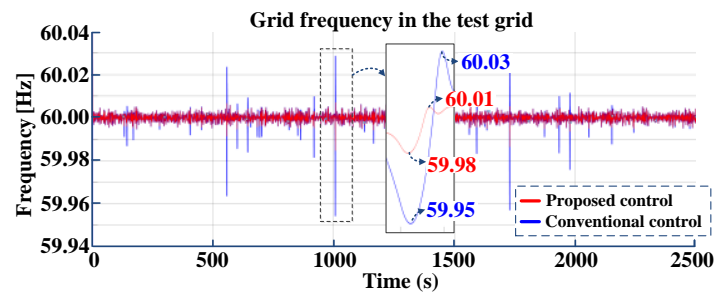

(b)

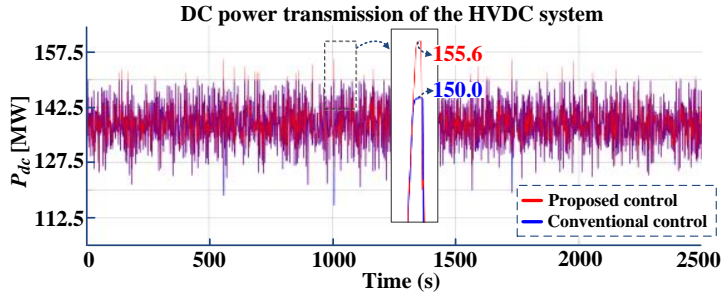

(c)

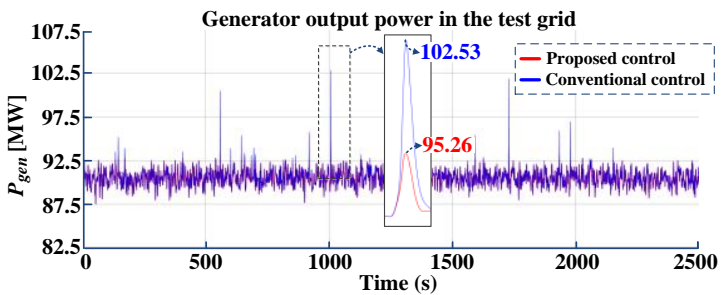

Fig. 15. (a) $\Delta f$, (b) $\Delta P_{d c}$, and (c) $\Delta P_{g e n}$ for the conventional and proposed control methods with respect to the continuous load demand variations

TABLE IV. RMS VARIATION IN THE FREQUENCY AND GENERATOR POWER

\begin{tabular}{c|ccc}
\hline & (1) Proposed & (2) Conventional & $((2)-(1)) /(2)[\%]$ \\
\hline \hline$\Delta f_{r m s}[\mathrm{~Hz}]$ & $2.12 \times 10^{-3}$ & $4.53 \times 10^{-3}$ & 53.2 \\
$\Delta P_{\text {gen, rms }}[\mathrm{MW}]$ & 2.11 & 2.37 & 11.0 \\
\hline
\end{tabular}

V. CONCLUSIONS

This paper proposes a new control scheme for an LCC HVDC system to increase the short-term operating margin of DC power transfer and improve the transient response by regulating both the voltage $V_{d c r}$ and current $I_{d c i}$. We developed the state space model of an LCC HVDC system for the conventional and proposed methods, and then conducted the root locus analysis particularly for a wide range of the DC line inductance and converter controller gains. Using the state space model, the responses of the HVDC system to the variation in the DC power reference were analyzed in simulations, where the actual Jeju-Haenam HVDC system was used as a test case. The simulation results demonstrated that the proposed method improves the short-term operating margin and transient response, so that the LCC HVDC system can be effectively utilized to provide fast-response ancillary services for the improvement of frequency regulation. The state space model can be used as a substitute for PSCAD models, with the significant benefit of time-efficiency.

Further work is required, particularly regarding the practical implementation of the proposed control method with the communications system between the rectifier and inverter controllers. The effects of communication failures or abnormal time delays on the performance of the proposed method need to be analyzed for its wide application. Another avenue of future research is to develop a state space model that incorporates commutation failures under AC voltage depression conditions. This will allow a more comprehensive analysis of the effects of $\mathrm{AC}$ line faults on the proposed method on a practical basis.

\section{APPENDIX}

\section{A. Equations for State Space Model of LCC HVDC System}

The DC and AC voltages at each HVDC converter side can be obtained from (15) and (16) [22].

$$
\begin{aligned}
& V_{d c x}=\frac{3 \sqrt{2} B}{\pi T_{x}} V_{l x} \cos \beta-\frac{3 X_{c x} B}{\pi} I_{d c x}, \quad(x, \beta)=(r, \alpha) \operatorname{or}(i, \gamma) \\
& V_{l x}=\frac{\sqrt{2} X_{c x} I_{d c x}}{\cos \beta-\cos \left(\beta+\mu_{x}\right)}=\frac{\sqrt{2} X_{c x} I_{d c x}}{2 \sin 0.5 \mu_{x} \sin \left(\beta+0.5 \mu_{x}\right)}
\end{aligned}
$$

The variations in $\alpha$ and $\gamma$ at the output ports of the PI controllers can be expressed as (17) [16].

$$
\Delta \beta=\left(s K_{p x}+K_{i x}\right)\left(\Delta T_{d c x}-\Delta T_{d c c_{-} r f f}\right),(x, \beta, T)=(r, \alpha, V) \operatorname{or}(i, \gamma, I)
$$

$\Delta I_{d c r}$ can then be expressed as

$$
\Delta I_{d c r}=\frac{s C}{1+s R C+s^{2} L C} \Delta V_{d c r}+\frac{1}{1+s R C+s^{2} L C} \Delta I_{d c i} .
$$

Using (15)-(18), (2) and (3) can then be expressed as

$$
\begin{gathered}
\Delta V_{d c r}=M_{1 r}\left(s K_{p r}+K_{i r}\right)\left(\Delta V_{d c r}-\Delta V_{d c r_{-} r e f}\right) \\
+M_{2 r}\left(\frac{s C}{1+s R C+s^{2} L C} \Delta V_{d c r}+\frac{1}{1+s R C+s^{2} L C} \Delta I_{d c i}\right) \\
\frac{1}{1+s R C+s^{2} L C} \Delta V_{d c i}-\frac{(R+s L)\left(2+s R C+s^{2} L C\right)}{1+s R C+s^{2} L C} \Delta I_{d c i} \\
=M_{1 i}\left(s K_{p i}+K_{i i}\right)\left(\Delta I_{d c c_{-} \text {erf }}-\Delta I_{d c i}\right)+M_{2 i} \Delta I_{d c i}
\end{gathered}
$$

Finally, (4) and (5) can be obtained by developing (19) and (20), respectively.

\section{B. Converting to Standard Form of State Space Equations}

The higher-order terms in (4) and (5) can be removed using the additional equations, expressed in matrix form:

$$
\left[\begin{array}{cccc}
n_{3} & n_{2} & n_{1} & 0 \\
1 & 0 & 0 & 0 \\
0 & 1 & 0 & 0 \\
0 & 0 & 1 & 0
\end{array}\right]\left[\begin{array}{c}
W_{0}^{(1)} \\
W_{1}^{(1)} \\
W_{2}^{(1)} \\
W_{3}^{(1)}
\end{array}\right]+\left[\begin{array}{cccc}
n_{4} & 0 & 0 & 0 \\
0 & -1 & 0 & 0 \\
0 & 0 & -1 & 0 \\
0 & 0 & 0 & -1
\end{array}\right]\left[\begin{array}{l}
W_{0} \\
W_{1} \\
W_{2} \\
W_{3}
\end{array}\right] .
$$

where $W=H, Y, U$, and $Z$. Therefore, (4) and (5) can be expressed as (7) where $[A],[B]$, and $[C]$ are developed by:

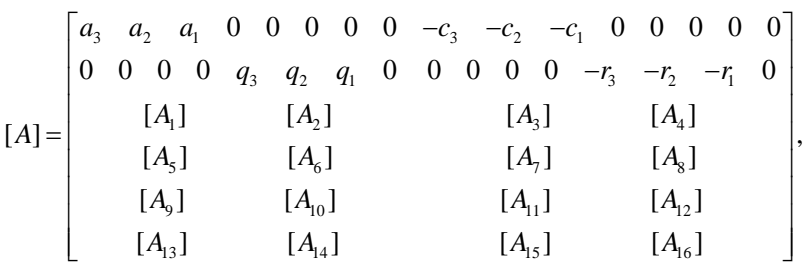

$$
\begin{aligned}
& {\left[A_{i}\right]=\left\{\begin{array}{l}
{\left[\begin{array}{llll}
1 & 0 & 0 & 0 \\
0 & 1 & 0 & 0 \\
0 & 0 & 1 & 0
\end{array}\right], i=1,6,11,16} \\
{[0]_{3 \times 4}, i \neq 1,6,11,16}
\end{array}\right.} \\
& {\left[B_{i}\right]=\left\{\begin{array}{l}
{\left[\begin{array}{llrr}
0 & -1 & 0 & 0 \\
0 & 0 & -1 & 0 \\
0 & 0 & 0 & -1
\end{array}\right], i=1,6,11,16} \\
{[0]_{3 \times 4}, i \neq 1,6,11,16}
\end{array}\right.}
\end{aligned}
$$




$[B]=\left[\begin{array}{cccccccccccccccc}a_{4} & 0 & 0 & 0 & b_{1} & 0 & 0 & 0 & 0 & 0 & 0 & 0 & 0 & 0 & 0 & 0 \\ p_{1} & 0 & 0 & 0 & q_{4} & 0 & 0 & 0 & 0 & 0 & 0 & 0 & 0 & 0 & 0 & 0 \\ & {\left[B_{1}\right]} & & & {\left[B_{2}\right]} & & & {\left[B_{3}\right]} & & & {\left[B_{4}\right]} & \\ & {\left[B_{5}\right]} & & & {\left[B_{6}\right]} & & & {\left[B_{7}\right]} & & & {\left[B_{8}\right]} & \\ & {\left[B_{9}\right]} & & & {\left[B_{10}\right]} & & & {\left[B_{11}\right]} & & & {\left[B_{12}\right]} \\ & {\left[B_{13}\right]} & & & {\left[B_{14}\right]} & & & {\left[B_{15}\right]} & & & {\left[B_{16}\right]}\end{array}\right]$

$[C]=\left[\begin{array}{lll}c_{4} & r_{4} & {[0]_{1 \times 12}}\end{array}\right]^{T}$

where

$$
\begin{array}{lrr}
a_{1}=-L C K_{p r} M_{1 r} & a_{2}=L C-M_{1 r}\left(R C K_{p r}+L C K_{i r}\right) \\
a_{3}=R C-M_{1 r}\left(K_{p r}+R C K_{i r}\right)-M_{2 r} C & a_{4}=1-M_{1 r} K_{i r} \\
b_{1}=-M_{2 r} \quad c_{1}=-L C K_{p r} M_{1 r} \quad c_{2}=-M_{1 r}\left(R C K_{p r}+L C K_{i r}\right) \\
c_{3}=-M_{1 r}\left(K_{p r}+R C K_{i r}\right) & c_{4}=-M_{1 r} K_{i r} \\
p_{1}=-1 & q_{1}^{2} C-L C K_{p i} M_{1 i} \\
q_{2}=2 R L C-M_{1 i}\left(K_{p i} R C+K_{i i} L C\right)+L C M_{2 i} & \\
q_{3}=R^{2} C+2 L-M_{1 i}\left(K_{p i}+R C K_{i i}\right)+R C M_{2 i} & \\
q_{4}=2 R-M_{1 i} K_{i i}+M_{2 i} & r_{1}=-L C K_{p i} M_{1 i} \\
r_{2}=-M_{1 i}\left(R C K_{p i}+L C K_{i i}\right) & r_{3}=-M_{1 r}\left(K_{p i}+R C K_{i i}\right) r_{4}=-M_{1 i} K_{i i}
\end{array}
$$

\section{REFERENCES}

[1] R. Zeng, L. Xu, L. Yao et al., "Hybrid HVDC for integrating wind farms with special consideration on commutation failure," IEEE Trans. Power Del., vol. 31, no. 2, pp. 789-797, Apr. 2016.

[2] R. H. Renner et al., "Ancillary services in electric power systems with HVDC grids," IET Gener., Transm., Distrib., vol. 9, pp. 1179-1185, 2015.

[3] L. Wang and M. N. Thi, "Stability enhancement of large-scale integration of wind, solar, and marine-current power generation fed to an SC-based power system through an LCC-HVDC link," IEEE Trans. Sustain. Energy, vol. 5, no. 1, pp. 160-170, Jan. 2014.

[4] L. Wang and M. N. Thi, "Comparisons of damping controllers for stability enhancement of an offshore wind farm fed to an OMIB system through an LCC-HVDC link," IEEETrans. Power Syst., vol. 28, pp. 1870-1878, 2013.

[5] L. Wang and M. N. Thi, "Stability enhancement of a PMSG-based offshore wind farm fed to a multi-machine system through an LCC-HVDC link," IEEE Trans. Power Syst., vol. 28, no. 3, pp. 3327-3334, Aug. 2013.

[6] G. Jang, S. Oh, M. Han et al., "Novel reactive-power-compensation scheme for the Jeju-Haenam HVDC system," IEEE Proc.- Gen., Transmiss., Distrib., Vol. 152, No. 4, pp. 514-520, Jul. 2005.

[7] B. E. Koh et al., "Introduction of Haenam-Jeju HVDC system," in Proc IEEE Int. Symp. Ind. Electron., Pusan, 2001, pp. 1006-1010.

[8] R. Li, S. Bozhko, and G. Asher, "Frequency control design for offshore wind farm grid with LCC-HVDC link connection," IEEE Trans. Power Electron., vol. 23, no. 3, pp. 1085-1092, May. 2008.

[9] B. Li, T. Liu, W. Xu et al., "Research on technical requirements of line-commutated converter-based high-voltage direct current participating in receiving end AC system's black start," IET Gener., Transm., Distrib., vol. 10, pp. 2071-2078, 2016.

[10]L. Fan, Z. Miao, and D. Osborn, "Wind farms with HVDC delivery in load frequency control," IEEE Trans. Power Syst., vol. 24, no. 4, pp. 1894 1895, Nov. 2009.

[11] J. Zhu, C. D. Booth, G. P. Adam et al., "Inertia emulation control strategy for VSC-HVDC transmission systems," IEEE Trans. Power Syst., vol. 28, no. 2, pp. 1277-1287, May. 2013.

[12] Y. Murata, M. Sakamaki et al., "Development of high voltage DC-XLPE cable system," in SET Technical Review, 2013, pp. 55-62.

[13]A. Gustafsson, M. Saltzer et al., "The new $525 \mathrm{kV}$ extruded HVDC cable system," ABB Grid Systems, Tech, Rep. Aug. 2014.

[14]IEEE Guide for Test Procedures for HVDC Thyristor Valves, IEEE Standard 857-1990, pp. 1-24, Feb. 1990.

[15] Y. Xue and X. P. Zhang, "Reactive power and AC voltage control of LCC HVDC system with controllable capacitors," IEEE Trans. Power Syst., vol. 32, no. 1, pp. 753-764, Jan. 2017.

[16]C. Karawita and U. D. Annakkage, "Multi-infeed HVDC interaction studies using small-signal stability assessment," IEEE Trans. Power Del., vol. 24, no. 2, pp. 910-918, Apr. 2009.
[17] A. Yogarathinam, J. Kaur, and N. R. Chaudhuri, "Impact of inertia and effective short circuit ratio on control of frequency in weak grids interfacing LCC-HVDC and DFIG-based wind farms," IEEE Trans. Power Del., vol. 32, no. 4, pp. 2040-2051, Aug. 2017

[18]X. Yang et al., "HVDC dynamic modelling for small signal analysis," IEEE Proc.-Gen. Transmiss. Distrib., vol. 151, no. 6, pp. 740-746, 2004.

[19]J. O'Reilly, A. R. Wood, and C. M. Osauskas, "Frequency domain based control design for an HVdc converter connected to a weak AC network," IEEE Trans. Power Del., vol. 18, no. 3, pp. 1028-1033, Jul. 2003.

[20]C. Osauskas and A. Wood, "Small-signal dynamic modeling of HVDC systems," IEEE Trans. Power Del., vol. 18, no. 1, pp. 220-225, Jul. 2003.

[21]D. Kwon et al., "Modeling of HVDC System to improve estimation of transient DC current and voltages for AC line-to-ground fault - an actual case study in Korea," Energies, vol. 10, no. 10, pp. 1-18, Oct. 2017.

[22] P. Kundur, Power System Stability and Control. Toronto, ON, Canada: McGraw-Hill, 1994, pp. 463-626.

[23] S. Nam, S. Kang, H. Nam et al., "Dynamic modeling of DFIG wind farms and HVDC for the power system in Jeju Island," in Proc. Int. Conf. Adv. Power Syst. Autom. Protect., Beijing, China, 2011, pp. 1951-1955.

[24]Z. Xu, S. Wang, and H. Xiao, "Hybrid high-voltage direct current topology with line commutated converter and modular multilevel converter in series connection suitable for bulk power overhead line transmission," IET Power Electron., vol. 9, pp. 2307-2317, Oct. 2016.

[25]R. Li, S. Bozhko, and G. Asher, "Frequency control design for offshore wind farm grid with LCC-HVDC link connection," IEEE Trans. Power Electron., vol. 23, no. 3, pp. 1085-1092, May. 2008.

[26] S. Chen, T. Zhang, H. B. Gooi et al., "Penetration rate and effectiveness studies of aggregated BESS for frequency regulation," IEEE Trans. Smart Grid, vol. 7, no. 1, pp. 167-177, Jan. 2016.

[27] R. Aouini, B. Marinescu, K. B. Kilani, and M. Elleuch, "Synchronverterbased emulation and control of HVDC transmission," IEEE Trans. Power Syst., vol. 31, no. 1, pp. 278-286, Jan. 2016.

[28]L. Wang and M. S. Thi, "Stability enhancement of a PMSG-based offshore wind farm fed to a multi-machine system through an LCC-HVDC link," IEEE Trans. Power Syst., vol. 28, no. 3, pp. 3327-3334, Aug. 2013.

[29] L. Wang and M. S. Thi, "Comparisons of damping controllers for stability enhancement of an offshore wind farm fed to an OMIB system through an LCC-HVDC link," IEEE Trans. Power Syst., vol. 28, no. 2, pp. 18701878, May. 2013.

[30]B. M. Yang, C. K. Kim, G. J. Jung et al., "Dynamic behavior of reactive compensation in Cheju-Haenam HVDC system," in Proc. Int. Conf. Electrical Machines and Systems, Nanjing, 2005, pp. 1313-1317.

[31]A. J. Ferre, Y. Pipelzadeh, and T. C. Green, "Blending HVDC-link energy storage and offshore wind turbine inertia for fast frequency response," IEEE Trans. Sustain. Energy, vol. 6, no. 3, pp. 1059-1066, Jul. 2015.

[32] Y. Liu, X. Cao, and M. Fu, "The upgrading renovation of an existing XLPE cable circuit by conversion of AC line to DC operation," IEEE Trans. Power Del., vol. 33, no. 3, pp. 1321-1328, Jun. 2017.

[33] Y. Song and C. Breitholtz, "Nyquist stability analysis of an AC-grid connected VSC-HVDC system using a distributed parameter DC cable model," IEEE Trans. Power Del., vol. 31, no. 2, pp. 898-907, Apr. 2016.

[34]F. B. Ajaei and R. Iravani, "Cable surge arrester operation due to transient overvoltages under DC-side faults in the MMC-HVDC link," IEEE Trans. Power Del., vol. 31, no. 3, pp. 1213-1222, Jun. 2016.

[35]M. K. Bucher and C. M. Franck, "Fault current interruption in multiterminal HVDC networks," IEEE Trans. Power Del., vol. 31, no. 1, pp. 87-95, Feb. 2016.

[36]Fast Response Regulation Signal, PJM [Online]. Available: http://www.pjm.com/markets-and-operations/ancillary-services/mkt-base d-regulation/fast-response-regulation-signal.aspx

[37]H. Wu, K. S. Tsakalis, and G. T. Heydy, "Evaluation of time delay effects to wide-area power system stabilizer design," IEEE Trans. Power Syst., vol. 19, no. 4, pp. 1935-1941, Nov. 2004.

[38] Y. G. Rebours, D. S. Kirschen, M. Trotignon, and S. Rossignol, “A survey of frequency and voltage control ancillary services-Part I: Technical features," IEEE Trans. Power Syst., vol. 22, no. 1, pp. 350-357, Feb. 2007.

[39] M. Yoon, Y. T. Yoon, and G. Jang, "A study on maximum wind power penetration limit in island power system considering high-voltage direct current interconnections", Energies, vol. 8, pp. 14244-14259, Dec. 2015.

[40]Z. Miao, L. Fan, D. Osborn, and S. Yuvarajan, "Wind farms with HVDC delivery in inertial response and primary frequency control," IEEE Trans. Energy Convers., vol. 25, no. 4, pp. 1171-1941, Dec. 2010.

[41] L. Harnefors, N. Johansson, and L. Zhang, "Impact on interarea modes of fast HVDC primary frequency control," IEEE Trans. Power Syst., vol. 32, no. 2, pp.1350-1358, Mar. 2017. 
Do-Hoon Kwon (S'15) received his B.S., M.S. Ph.D. degrees in Electrical Engineering from Seoul National University in 2010, 2012, and 2018, respectively. He is currently working as a research professor in the Department of Electrical Engineering at Myongji University.

His research fields of interest include HVDC systems, energy management systems, and smart distribution systems.

He was selected as the recipient of the Best Reviewer Award for IEEE Transactions on Smart Grid in 2017.

Young Jin Kim (S'14-M'15) received the B.S. and M.S. degree in Electrical Engineering from Seoul National University in 2007 and 2010, respectively, and his Ph.D. degree in Electrical Engineering from Massachusetts Institute of Technology in 2015.

He worked for Korea Electric Power Corporation as a power transmission and distribution system engineer from 2007 to 2011. He was also a visiting scholar at the Catalonia Institute for Energy Research in 2014, and a postdoctoral researcher for Center for Energy, Environmental, and Economic Systems Analysis at the Energy Systems Division at Argonne National Laboratory from 2015 to 2016.

He joined the faculty of the Pohang University of Science and Technology (POSTECH), where he is currently an Assistant Professor in the Department of Electrical Engineering. His research fields of interest include distributed generators, renewable energy resources, and smart buildings.

Dr. Kim is the Editor of the IEEE Transactions on Smart Grid.

Seung-IIl Moon (M'93-SM'14) received the B.S. degree in electrical engineering from Seoul National University, Seoul, Korea, in 1985, and the M.S. and Ph.D. degrees in electrical engineering from Ohio State University, Columbus, in 1989 and 1993, respectively.

$\mathrm{He}$ is currently a Professor of the School of Electrical Engineering and Computer Science at Seoul National University.

Mr. Moon's awards and honors include the Service Merit Medal (Korean Government), Young-Moon Park Best Scholar Award and Outstanding Scholar Award (Korean Institute of Electrical Engineers). 